\title{
Out of the shadows - changes in women's reproductive health
}

\section{Safe, legal abortions and comprehensive reproductive health care are crucial for women, but there is still a long way to go}

$\mathrm{t}$ was the first autopsy I attended and it left a lifelong impression. The year was 1970, and I was a medical student in Dublin. A young woman had come from the country to work in a bank. She became unwell and was cared for by her landlady, who diagnosed the flu. When her condition worsened, she refused a doctor until she was moribund. By the time an ambulance was called, she had developed septicaemia, and she died soon after reaching hospital. The autopsy revealed extensive peritonitis and infected placental tissue in the uterus, which showed signs of interference, although by whom, or where, or when was never established, as was often the case.

As a junior doctor in Papua New Guinea in the 1970s I was to see more such deaths among women who had wanted to conceal their pregnancies, consuming toxic herbs or using sticks to try to induce an abortion. In particular, I remember a nursing student from a distant province. Top of her class in her home village, she had come to Port Moresby to train. Like the Irish bank-teller, she was too terrified to seek help until it was too late.

Those experiences provided much of my motivation for advocating - with many others — reforms in women's reproductive health care in Australia, in particular the introduction of mifepristone (RU486) for medical abortion and the decriminalisation of abortion in state legislation.

Over 40 years, I have seen many advances in my chosen specialty of obstetrics and gynaecology. When I began training, the only use of ultrasound was to locate the placental site after antepartum haemorrhage. Now, sophisticated ultrasound techniques are used on a daily basis to assess both normal and abnormal pregnancies. Perinatal mortality rates have dropped to a fraction of what they were due to closer fetal surveillance, and we have better management of diabetes and pre-eclampsia, and better facilities for care of pre-term babies. In-vitro fertilisation now enables many women, who would have previously remained childless, to give birth. There has been great progress in hormonal contraception, and the progestogen intrauterine device has made a huge difference to management of menstrual disorders, so that hysterectomy, common 20 years ago, is much less needed.

However, I believe that among all these advances, the most dramatic and beneficial development in the provision of women's health care in this time has been the change from unsafe, clandestine abortion to safe, open practice.

In Australia, as in most other developed countries, there has been abortion law reform. Of course, there is still a long way to

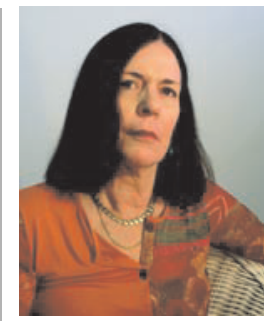

Caroline M de Costa PhD, FRANZCOG, FRCOG Professor of Obstetrics and Gynaecology

School of Medicine and Dentistry, James Cook University, Cairns, QLD.

caroline.decosta@ jcu.edu.au

doi: 10.5694/mjall.11264

Makingabortion ... widely and safely available [can] prevent many maternal deaths go. Only some states and territories have reformed or decriminalised their quaintly worded 19th-century legislation. But even without reform, case law has made the provision of abortion less uncertain for doctors, and more accessible for women.

Medical abortion using mifepristone remains available only in restricted circumstances in Australia, and generally only to urban women; hopefully, in the near future, the drug will be accessible to all Australian women.

Abortion is now much more widely discussed in society generally, as well as in the medical literature. There is increasing recognition that abortion is an important health issue for Australian women.

However, there are still many countries in the developing world, including Papua New Guinea, where women die or suffer chronic ill health from complications of unsafe abortion. Making abortion, in particular medical abortion, widely and safely available has the potential to prevent many maternal deaths.

Like everybody else interested in improving women's health, I would like to see abortion rates reduced in Australia and elsewhere. However, this needs to be achieved by reducing the rates of unplanned and unwanted pregnancies, rather than by forcing reluctant women to continue their pregnancies. In Australia, certainly, effective contraception is available, including a variety of hormonal preparations. There are intrauterine devices with minimal side effects and long life spans, and the morning-after pill can be bought over the counter in Australian pharmacies. Yet our abortion rates are still more than three times higher than those of Belgium, the Netherlands and Scandinavia, where there are very liberal abortion laws and accessible abortion services. Clearly, we are not providing effective sex education at a standard equal to these countries.

Little attention is given to contraceptive information and services in the course of antenatal and postnatal care, especially in the public sector. A more integrated system of women's reproductive health care is needed, in which sexual health care, contraceptive advice and provision, prepregnancy and pregnancy advice, and care during and after pregnancy and birth would complement one another. Such a system would also incorporate abortion provision into mainstream health care. All women should have access to appropriate information and care in pregnancy, regardless of whether or not they intend to continue that pregnancy.

I look forward to working towards improvements in abortion provision, and in other aspects of women's reproductive health care, for the rest of my professional life.

Competing interests: No relevant disclosures.

Provenance: Commissioned; not externally peer reviewed. 